\title{
Fast underwater bonding to polycarbonate using photoinitiated cyanoacrylate
}

\author{
William E. Cloete, Walter W. Focke* \\ Institute of Applied Materials, Department of Chemical Engineering, University of Pretoria, Pretoria, South Africa
}

\begin{abstract}
Rapid underwater bonding of clear polycarbonate to metal or plastic substrates at temperatures approaching $0{ }^{\circ} \mathrm{C}$ was studied. Bonding was achieved within minutes using ethyl 2-cyanoacrylate gel cured using the photoinitiator (dibenzoylferrocene) with a blue-LED light source. The optimum initiator concentration varied from $0.3 \%$ to $0.1 \mathrm{wt} \%$ for adhesive films 0.5 to $1.2 \mathrm{~mm}$ thick respectively. The polymerisation rate shows a negative temperature dependence making it highly suitable for cold environments. The ultimate shear strength of the bonds was temperature independent and ranged from $1 \mathrm{MPa}$ for metallic to $5 \mathrm{MPa}$ for plastic substrates respectively.
\end{abstract}

Keywords: Cyanoacrylates (A), destructive testing (C), thermal analysis (C), cure/hardening (D), underwater bonding.

\section{Introduction}

Neat cyanoacrylate reacts rapidly when it comes in contact with water. It is therefore not generally used for underwater bonding. However, the cured resin is not much affected by exposure to water. Consequently this adhesive finds interesting underwater applications including tagging of sea mammals [1] and mussels or scallops [2] and fixing coral to rocks underwater [3]. Numerous other applications are described in the patent literature [5, 6, 7]. This study considered the use of a commercial an ethyl cyanoacrylate-based adhesive for underwater bonding of clear polycarbonate sheets to other substrates for use with a proprietary applicator system. The key idea of the applicator is to use the adhesive itself to rapidly displace any water present between the two substrates to be bonded. This is achieved by extruding the adhesive from a central application hole. The water displacement is best achieved using a high-viscosity adhesive. Suitable thickening agent, e.g. fumed silica, can be used to impart the required consistency. Previous studies [5] showed that the strongest bonds are achieved with thin adhesive layers. Thicker adhesive sections take a longer time to cure and sometimes full cure is not achieved.

Since the present application requires rapid bonding of a clear polycarbonate sheet to flat underwater substrates, photoinitiated cure was a definite option. Photoinitiated curing of acrylate adhesives is well established $[8,9,10]$ and commercial systems are available [11]. The advantage is that photoinitiated cure can be initiated on demand and that thicker adhesive sections polymerize to completion. Thus this study considered the addition of an anionic photoinitiator to the cyanoacrylate adhesives to act as the primary cure initiator.

Ferrocene is a transition metal complex that has been the subject of numerous investigations [12]. The photochemical characteristics of ferrocene and several of its derivatives have been studied exhaustively [13, 14, 15]. Kutal and Yamaguchi [16] identified dibenzoylferrocene as a preferred anionic photoinitiator for cyanoacrylates. It is insoluble in water and has a maximum absorption peak at $485 \mathrm{~nm}$. This closely matches the $470 \mathrm{~nm}$ blue LED light sources used in underwater camphorquinone initiated acrylate systems [8, 9, 10]. This light source was therefore selected for used in the present study.

\footnotetext{
${ }^{*}$ Corresponding author. E-mail: walter.focke@up.ac.za
} 


\section{Materials and Methods}

\subsection{Adhesives and Substrates}

A commercial ethyl cyanoacrylate gel (Loctite 454) was used without modification.

Dibenzoylferrocene was supplied by Sigma Aldrich Chemicals and used without further purification as a solution in hexane. Sea water was simulated using the aquarium product 'Ocean Fish' supplied by Prodac. All other chemicals used were obtained from Sigma Aldrich. Metal sheets (hot-rolled mild steel sheet (12\% carbon), stainless steel 304, and aluminium) were cut into squares measuring $10 \times 100 \times 100 \mathrm{~mm}$ in accordance with ASTM D 4501. The bonding surfaces of the different metal substrates were sanded with 100 grit sandpaper and then cleaned with a lint-free cloth soaked in isopropyl alcohol. The sulphuricacid anodised aluminium was used as supplied. All thermoplastic sheets were supplied by Maizeys. The fibre-reinforced polyester (FRP) sheet was cast using glass fibre and polyester resin supplied by Plastocure.

\subsection{Light Sources and Calibration}

The light source unit was custom-designed and consisted of 144 LED's in a 12 x 12 array. Nichia Corporation (Model: NSPB 500S) 5 mm blue ultra-bright LED's were used. The whole system was sealed inside an acrylic box to allow underwater illumination of the substrates. The light source was powered by a Vanson Deluxe Universal Regulated DC Power Supply (Model RC-1200). The output was set at 12 V DC and the overall current measured was $750 \mathrm{~mA}$. The light source was calibrated by the National Metrology Institute of South Africa (NMISA) by comparing the spectral irradiance of the blue light LED array against the spectral irradiance of a standard lamp, traceable to the national measuring standard for spectral irradiance. In this investigation the adhesive was illuminated with the light source placed at a distance of $50 \mathrm{~mm}$ away. This distance was chosen to ensure overlapping of the individual LED light beams and to allow sufficient space to fit the experimental equipment between the light source and the adhesive samples. All adhesive samples were irradiated at an effective light intensity of $5 \mathrm{~mW} / \mathrm{cm}^{2}$.

\subsection{Photodifferential Scanning Calorimetry (Photo-DSC)}

Isothermal photopolymerisation studies were performed on a Perkin-Elmer DSC-7 differential scanning calorimeter and analyzed using Pyris software. An indium standard was used for calibration. The DSC head was modified with a single polycarbonate window covering both the sample and the reference cells as described by Pappas [17]. The polycarbonate window was regularly replaced because, over time, vapours from the cyanoacrylate samples affected its transparency. The blue LED light source was positioned at a distance of $50 \mathrm{~mm}$ above the measuring pans. The light source was switched on and off using a timer.

Cylindrical aluminium sample pans were used with depths of $0.5,0.8$, and $1.2 \mathrm{~mm}$ to control the sample thickness. Nitrogen was used as the purge gas. The instrument was allowed to stabilize at every set isothermal temperature before photocuring experiments commenced.

\subsection{Tensile Testing}

The shear strength of the adhesive bonds between the rigid substrates was measured according to the ASTM D4501 shear block testing standard on an Instron 4303 tensile tester. The load cell had a maximum capacity of $25 \mathrm{kN}$ in tension. Shear strength values reported here are averages of at least five replicates in accordance with the ASTM specification.

\subsection{Bonding Process}

The application process is a vital factor that determines the ultimate strength of underwater bonds. In this study the top substrate was always a clear polycarbonate sheet. This allowed facile illumination of the adhesive sandwiched between the two substrates. 
A $19 \mathrm{~mm}$ diameter pencil ring was drawn in the centre of the polycarbonate sheet used as the top substrate. A quantity of $0.50 \mathrm{~g}( \pm 0.01 \mathrm{~g})$ of adhesive was placed on this demarcated area. This was done to keep the surface area of the adhesive, exposed to water, constant. The bottom substrate was first submerged in water. It was left in the water bath for at least 5 minutes to allow temperature equilibration. The top substrate was then submersed into the water bath and pressed firmly onto the bottom substrate. This action caused the adhesive to flow radially outward and cover the entire bond area. Next the light source was submersed. It was positioned at a distance of $50 \mathrm{~mm}$ away from the bond line and switched on to initiate cure.

It should be noted that rapid polymerization of the cyanoacrylate resin ensues as soon as it comes in contact with water. However, this gives rise to a protective skin layer that acts as a barrier for further water ingress by diffusion $[5,6]$. Thus only the adhesive's outer surface (inside the $19 \mathrm{~mm}$ ring on the top substrate) is instantly affected by the exposure to water. This part of the cyanoacrylate adhesive, cured by the reaction with water, assumes a white colour. This contrasts with the orange tint of cyanoacrylate cured by the blue light radiation. Since the white-coloured skin represents already polymerised material, it does not contribute to the bonding of the bottom substrate. When the two sheets are pressed together, the protective skin ruptures and adhesive is squeezed out. The uncured adhesive displaces the water as it travels radially outwards between the two substrates. Only this part of the surface is responsible for the measured bond strength. The non-bonded water-cured skin region trapped between the two substrates had an average diameter of $21 \mathrm{~mm}$. This inactive bond area $\left(346 \mathrm{~mm}^{2}\right)$ was subtracted from the total bond area $\left(2500 \mathrm{~mm}^{2}\right)$ to give, on average, an active bond area of $2154 \mathrm{~mm}^{2}$ for calculating the shear bond strength. The average bond line thickness was measured at $0.2 \mathrm{~mm}$.

The effect of illumination time and water temperature on the ultimate bond shear strength was determined using polycarbonate as top and bottom substrates. The sheets were bonded in potable water. The effect of illumination time was determined using a water temperature of 15 ${ }^{\circ} \mathrm{C}$. Next the illumination time was kept constant at 1 minute and the water temperature varied from 1.5 to $40^{\circ} \mathrm{C}$. Bond strength measurements to various other substrate materials were done on samples bonded in $15^{\circ} \mathrm{C}$ potable water as well as in simulated sea water. The different materials tested are categorised as metals (mild steel, aluminium, anodised aluminium, stainless steel 304) and other polymers including ABS (Acrylonitrile-butadiene-styrene), poly(vinyl chloride) (PVC), poly(methyl methacrylate) (PMMA), polycarbonate (PC), and fibreglass-reinforced polyester (FRP). Substrate preparation was the same in each case and an illumination time of 1 minute was used throughout.

The effect of the length of time for which the adhesive was exposed to water before bonding studied by delaying the pressing together of the sheets for predetermined times. These tests were performed in potable and in artificial sea water at a temperature of $15^{\circ} \mathrm{C}$.

In all cases the actual shear bond strengths were measured at room temperature. The averages of at least five replications are reported.

\section{Results and Discussion}

\subsection{Thermal Analysis}

\subsubsection{Experimental Problems with Photo-DSC}

The cure reaction of cyanoacrylates is highly exothermic and calorimetric techniques seem ideal to study the polymerization kinetics. Cyanoacrylates are among the most reactive monomers to be examined kinetically. Pepper and co-workers $[18,19]$ studied their cure kinetics and the mechanism of polymerisation. Despite the fact that they employed carefully controlled experimental conditions, problems were experienced with respect to reproducibility. Similar problems were experienced in this study where the polymerisation of cyanoacrylate adhesives was followed using photo-DSC. 


\subsubsection{Effect of Photoinitiator Concentration}

It is conventional to assume that the DSC-measured heat flux is proportional to the rate of polymerization. The amount of photoinitiator (PI) present, affects the rate of polymerisation. Thus experiments were conducted varying both the concentration of dibenzoylferrocene and the adhesive film thickness. Since the idea was to simulate actual underwater bonding conditions, relatively thick films $(0.5-1.2 \mathrm{~mm})$ were tested in order to determine the optimum photoinitiator concentration. The photoinititiated DSC cure studies revealed complex cure behaviour. The measured cure rates were not sufficiently repeatable to allow a proper kinetic analysis of the data. Consequently the cure time was simply characterized by the time required to attain $95 \%$ of the full conversion time $\left(t_{95}\right)$. For a given experiment, this was calculated as the time point where $95 \%$ of the total heat release, due to the reaction exotherm, was reached. The optimum photoinitiator concentration was associated with the shortest cure time.

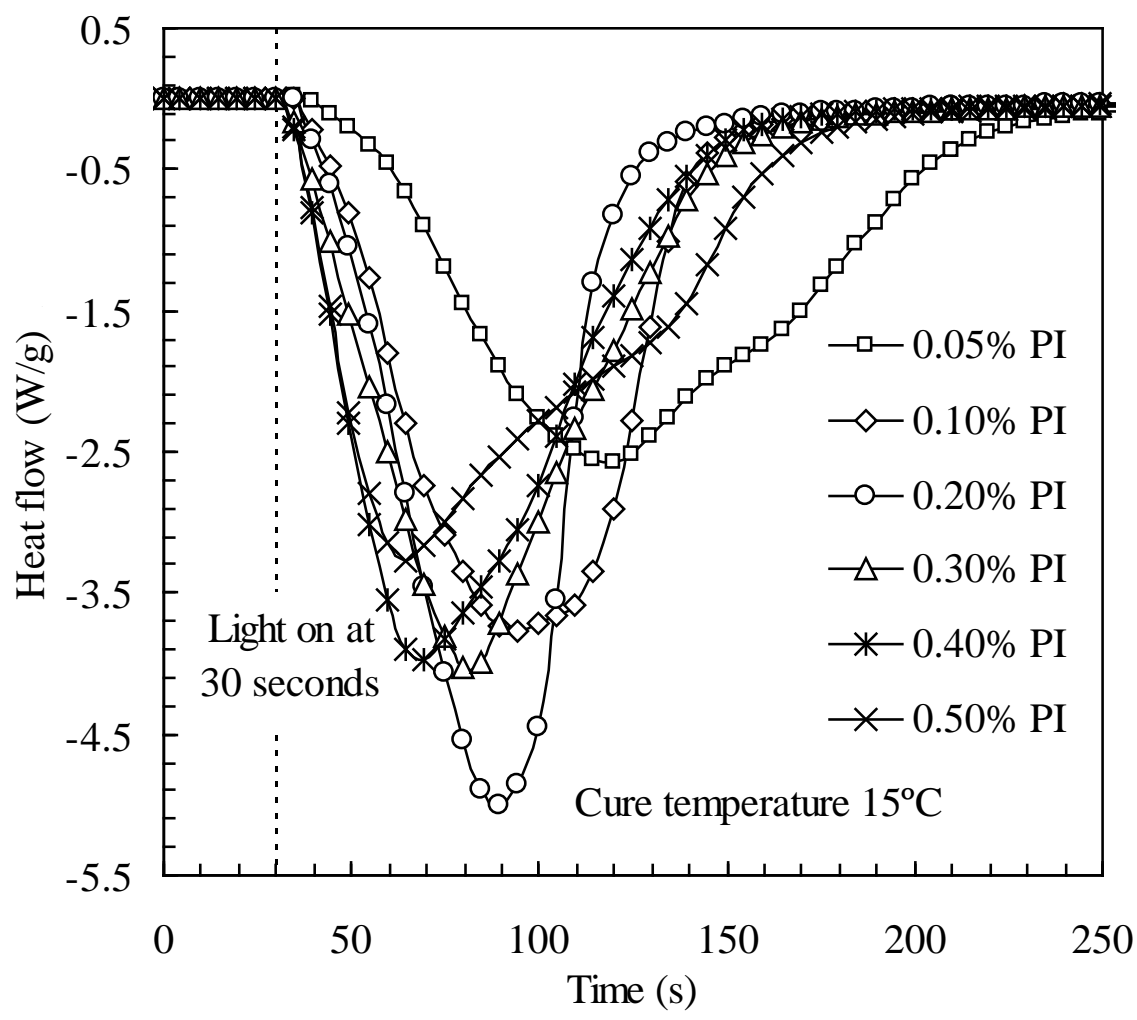

Figure 1: Effect of the photoinitiator concentration on the isothermal cure exotherms for Loctite 454

Figure 1 shows DSC exotherms measured at a film thickness of $0.8 \mathrm{~mm}$. The peak in the exotherm corresponds to the maximum rate of polymerization. Figure 1 reveals that the maximum cure rate first increases and then decreases with increasing photoinitiator concentration. This counterintuitive behaviour can be rationalized as follows: Cure initiation is hampered by the acidic stabiliser. This means that the stabilizer neutralization reaction competes with the cure initiation reaction. Consequently it takes an even longer time to reach the maximum cure rate when the concentration of initiator is low. At intermediate photoinitiator concentrations the maximum cure rate is reached in a very short time. However, at higher concentrations the exotherm 'tails out', i.e. takes a longer time to return to the base line. This is attributed to excessive light absorption by the outer layers hampering photoinitiation of the deeper layers, the so-called "the inner filter effect". Similar exotherm trends were observed for experiments conducted with adhesive film thicknesses of 0.5 and $1.2 \mathrm{~mm}$. 
Nevertheless the overall heat of reaction was independent of initiator concentration and film thickness and amounted to $262 \pm 4 \mathrm{~J} / \mathrm{g}$.

Figure 2 shows the effect of initiator concentration and film thickness, at a temperature of 20 ${ }^{\circ} \mathrm{C}$, on the cure time. As mentioned, this was taken as the time to reach $95 \%$ conversion $\left(\mathrm{t}_{95}\right)$. Generally and unsurprisingly, the thicker the film, the longer is the cure time $\left(t_{95}\right)$. The cure time curves obtained by a plot against the initiator concentration show shallow minima. The minimum cure time and corresponding initiator concentration increases with increasing film thickness in accordance with expectations considering the "inner-filter" effect [20]. The optimum concentration of dibenzoylferrocene for the polymerisation of films of $0.5,0.8$ and $1.2 \mathrm{~mm}$ are approximately $0.28,0.2$ and $0.14 \mathrm{wt} \%$.

In the current underwater adhesion tests, the average bond line thickness was observed to be slightly less than $0.2 \mathrm{~mm}$. This means that a photoinitiator concentration of $0.3 \mathrm{wt} \%$ or a little higher would probably provide the fastest cure. It was, however, decided to standardize on 0.2 wt \% photoinitiator in all further testing because real life underwater surfaces are generally rather rough and one would therefore expect that thicker adhesive lines may be encountered.

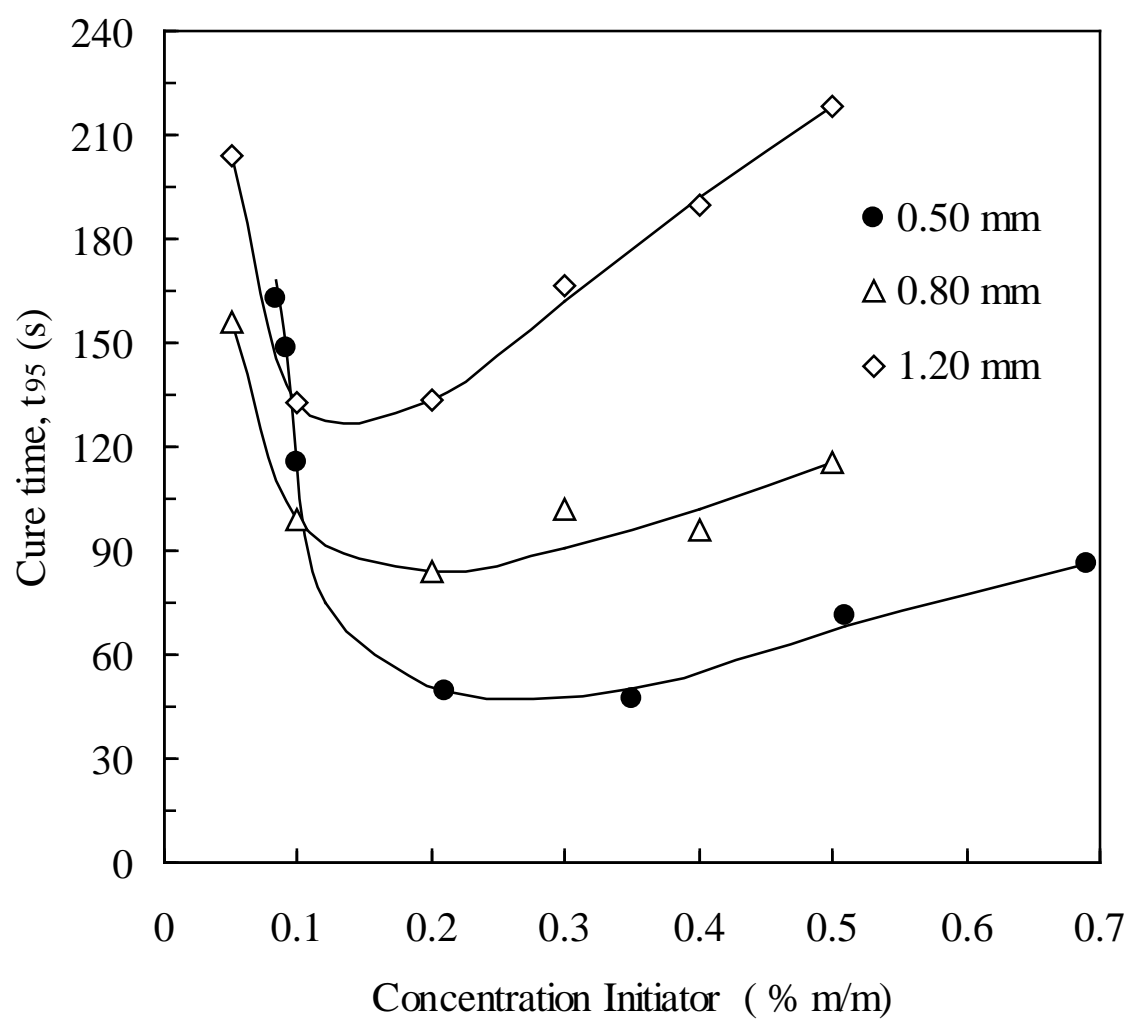

Figure 2: The effect of photoinitiator concentration and adhesive film thickness on the cure time $\left(\mathrm{t}_{95}\right)$.

\subsubsection{Effect of photopolymerisation temperature}

Isothermal photopolymerisation experiments were performed at temperatures of $-10,20$ and $50{ }^{\circ} \mathrm{C}$. Owing to the poor reproducibility of the data, each curve in Figure 3 actually represents the average of ten separately measured exotherms. The exotherms in Figure 3 show that the cure advances faster at lower reaction temperatures in agreement with previous studies dealing with ferrocene derivatives [21, 22], or aliphatic amines and pyridine derivatives [19] as initiators. 


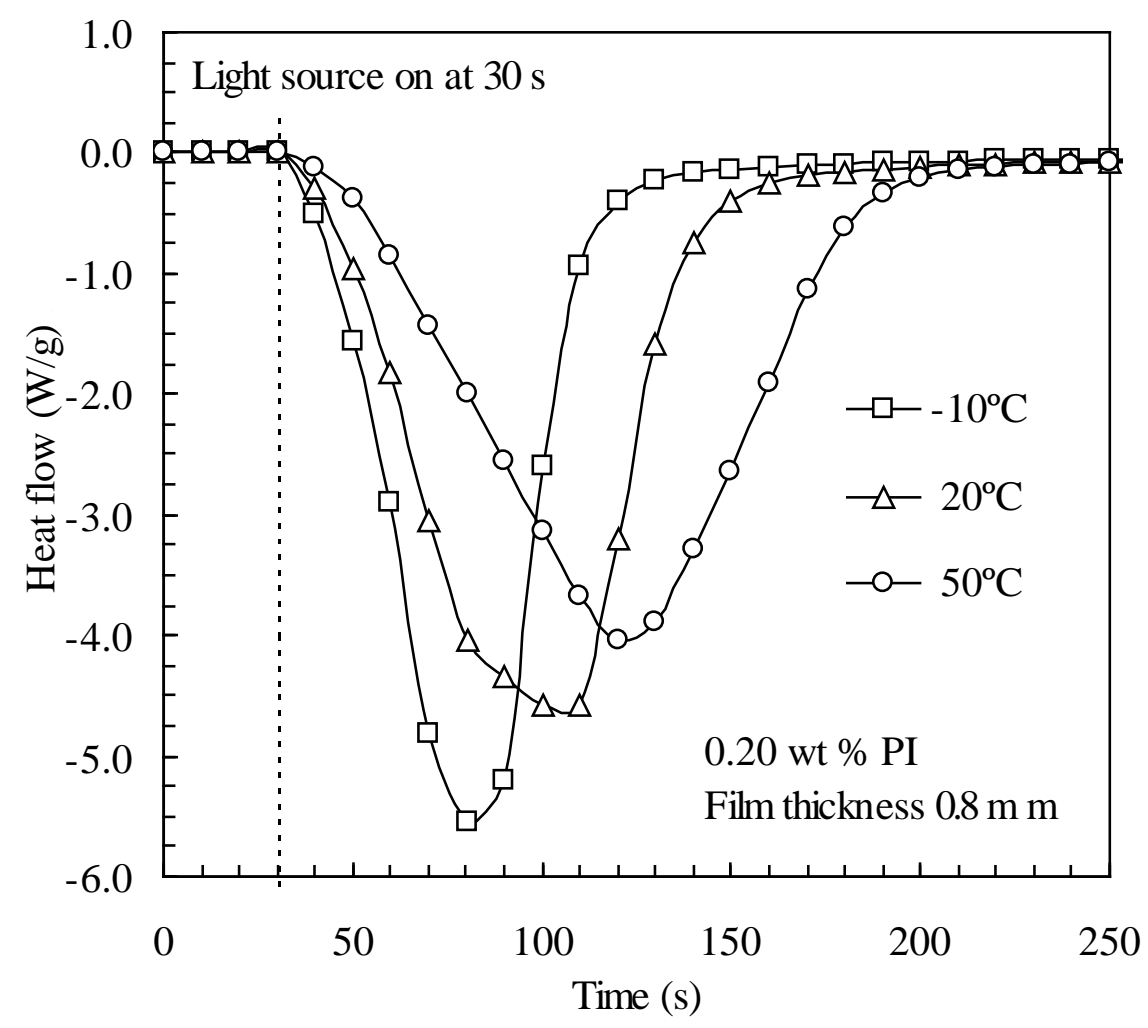

Figure 3: Averaged DSC cure exotherms obtained at different temperatures

These results indicate that this adhesive system will cure faster in cold water conditions. This gives it an advantage over epoxy-based underwater adhesives which often fail to cure properly under such cold conditions. If it is assumed that the $95 \%$ conversion state is controlled by a single reaction with its associated Arrhenius activation energy, the effective cure time (in seconds) for $0.80 \mathrm{~mm}$ thick adhesive containing $0.20 \%$ initiator is given by the expression

$$
t_{95}=1495 e^{-782 / T}
$$

\subsection{Bond Strength Results}

\subsubsection{Illumination Time}

Figure 4 shows the effect of illumination time on ultimate bond shear strength obtained in potable water at $15{ }^{\circ} \mathrm{C}$ with polycarbonate as both top and bottom substrate. The bond strength increases with increased illumination time but reaches a plateau value beyond 50 seconds. An advantage offered by the cyanoacrylates over standard acrylic adhesives [8-10] is that a useful level of bond strength develops even in the absence of illumination.

\subsubsection{Substrate Material}

Figure 5 shows the shear bond strengths achieved for bonds of polycarbonate to other substrates. It is clear that the adhesive bonds to polymeric substrates were much stronger than those to metals. For mild steel and aluminium the failure mode was adhesive failure at the metal surface. Visual inspection revealed the presence of patchy moisture films on the bared metal. This implies that the adhesive was unable to completely and effectively remove water from the metal surface during the bonding process. 


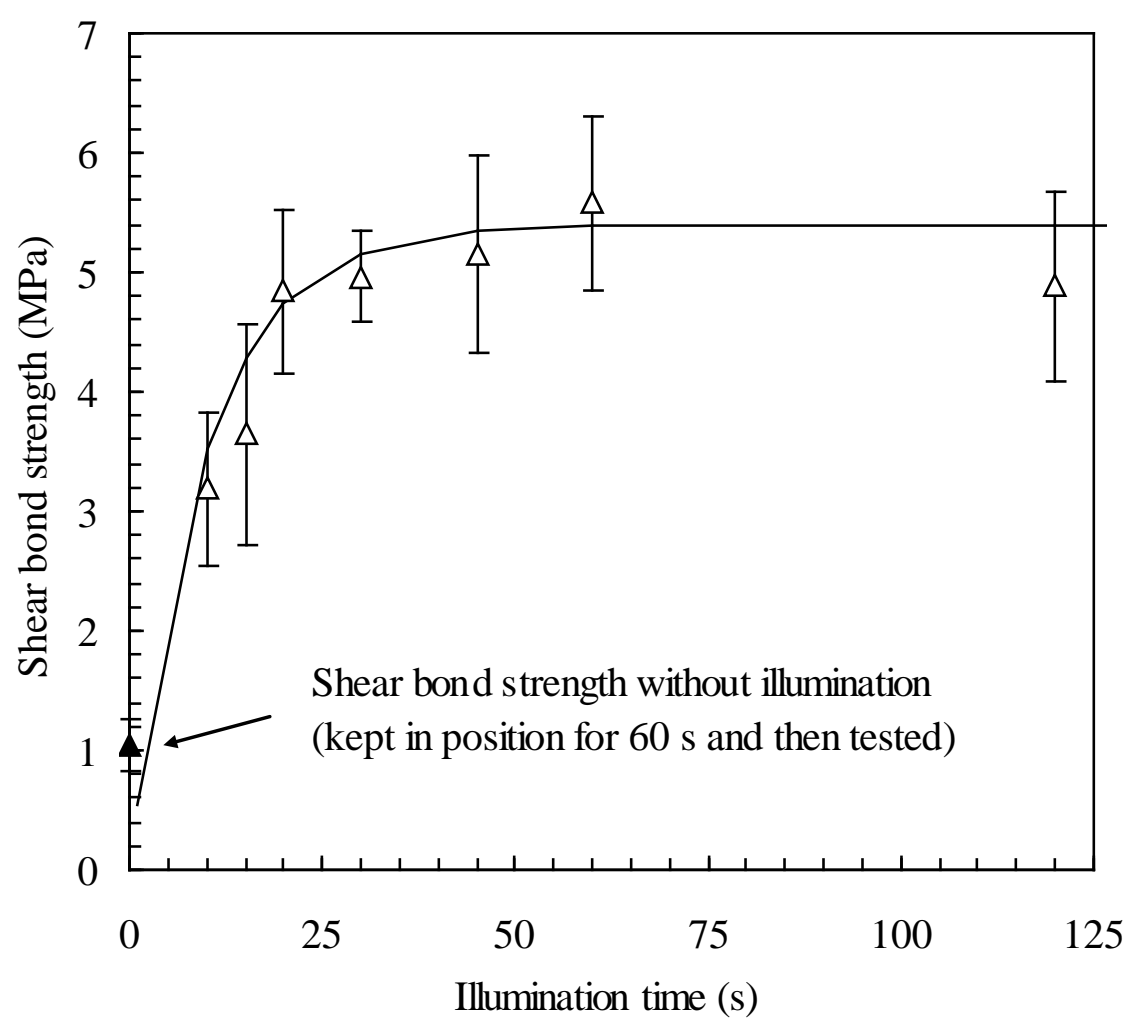

Figure 4: The effect of illumination time on the shear strength of polycarbonate bonded to polycarbonate

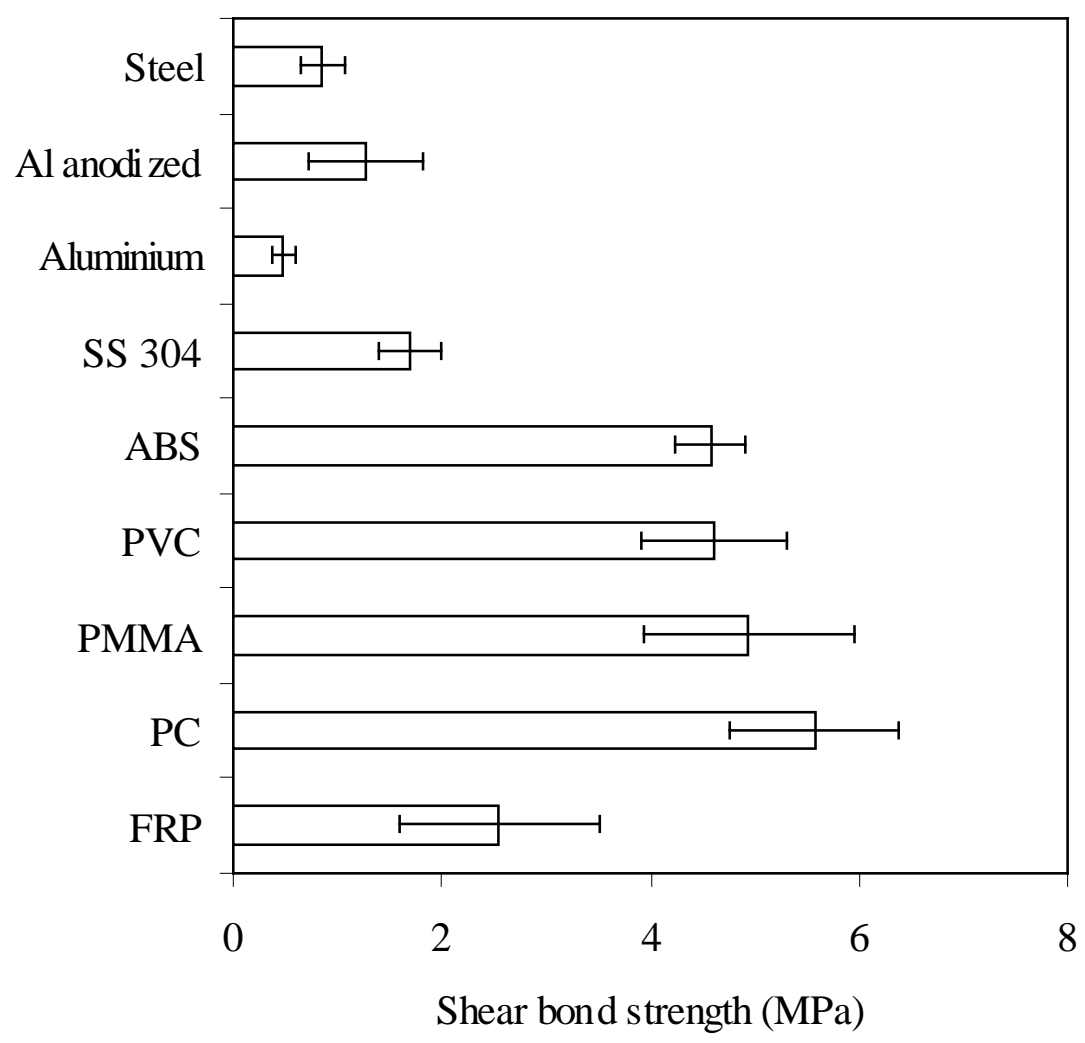

Figure 5: Shear strength for polycarbonate bonded to other substrate materials 
Low shear bond strengths of 0.86 MPa and 0.49 MPa were recorded for mild steel and aluminium respectively. Bonding was more effective with the anodised aluminium averaging 1.27 MPa, i.e. more than double the strength obtained with untreated aluminium. In this case the failure mode was mixed. It occurred mainly between the anodised layer and the metal surface, revealing the shiny metal surface underneath the grey anodised layer. In minor parts cohesive failure of in the adhesive layer was also observed. Kinloch [23] also reported this type of failure mode for aluminium surfaces anodised with sulphuric acid. Adhesion to stainless steel 304 was somewhat better than to anodised aluminium. The failure mode was mixed with small amounts of adhesive present on the stainless steel surface after bond failure. All the bonds made to polymers showed varying degrees of cohesive failure, except for the FRP which showed massive substrate failure. The average shear bond strength to polymers was in the order of $5 \mathrm{MPa}$. Drain et al. [24, 25] found than cyanoacrylates dissolve polycarbonate to form a type of "solvent" welded interface that is able to withstand moisture over long periods. Whether cyanoacrylate adhesives have the ability to do the same to other polymers like ABS, PVC, PMMA and FRP is not clear, but very high bond strengths are measured on these materials. The large difference in shear bond strength between metallic and polymeric materials could be attributed to their respective hydrophilicities. Metallic surfaces tend to be more hydrophilic and polymeric surfaces more hydrophobic. It is more difficult for the cyanoacrylate adhesive to completely displace the water from immersed metal surfaces and ensure the good initial contact necessary for the development of strong bonds.

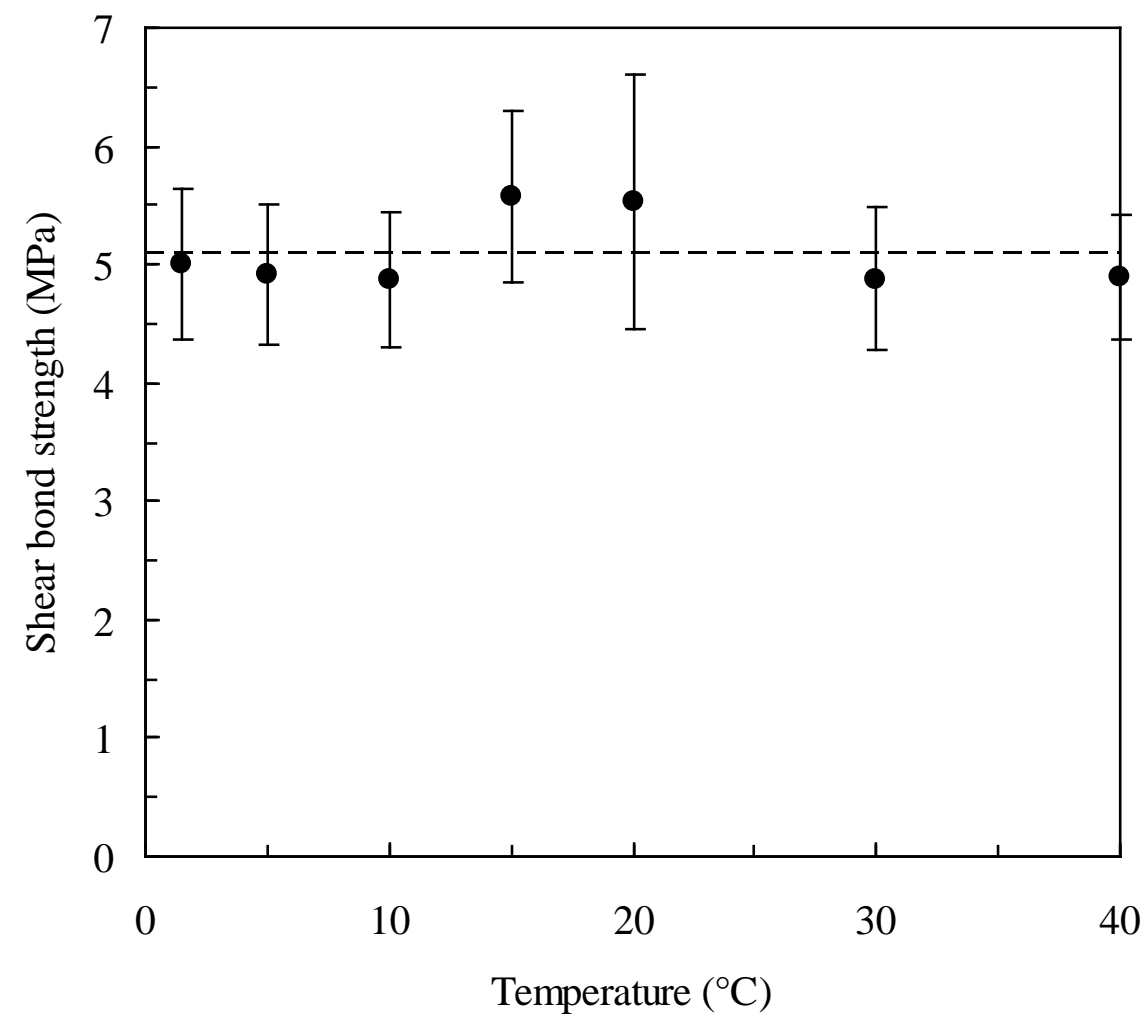

Figure 6: Effect of temperature on shear bond strength

\subsubsection{Effect of Temperature}

Figure 6 shows that varying the water temperatures between 1.5 and $40{ }^{\circ} \mathrm{C}$ did not significantly influence the bond strength. Although photo-DSC data revealed negative temperature dependence, i.e. a lower rate of cure at high temperatures, this did not affect the ultimate bond strength obtained at $40{ }^{\circ} \mathrm{C}$. It can therefore be concluded that the 1-minute 
illumination time on a bond $0.2 \mathrm{~mm}$ thick adhesive layer cured at $40{ }^{\circ} \mathrm{C}$ was sufficient to achieve the full bonding.

\subsubsection{Effect of Water Exposure Time}

Unlike acrylate-based adhesives, cyanoacrylates react when coming in contact with water. On submersion, the outer layer of the cyanoacrylate adhesive (clear with a light orange tint) rapidly polymerises to form a white protective barrier skin. This skin is permeable and water ingress via diffusion will slowly cause polymerization of the remaining adhesive on the inside until all of it has been converted. Preliminary measurements indicate that in room-temperature potable water the polymerized cyanoacrylate skin grew to a thickness of about $1.5 \mathrm{~mm}$ in one hour. It is therefore imperative that the bond should be made as soon as possible after submersion, i.e. contact with water. Figure 7 shows the effect of water exposure time on the shear bond strength. It shows a linear decline in bond strength with water exposure time. The bond strength decays slightly faster in artificial sea water, possibly due to the $\mathrm{pH}$ being higher than that of potable water. This accords with the findings of Katti and Krishnamurti [26] who found that alkyl cyanoacrylates polymerize faster in higher $\mathrm{pH}$ environments. The reduction in bond strength is due to a combination of two factors: the reduction in the amount of adhesive available for bonding and therefore a smaller bonding area, and the increase in bond line thickness due to the PECA skin which becomes thicker over time causing the bond line to be thicker.

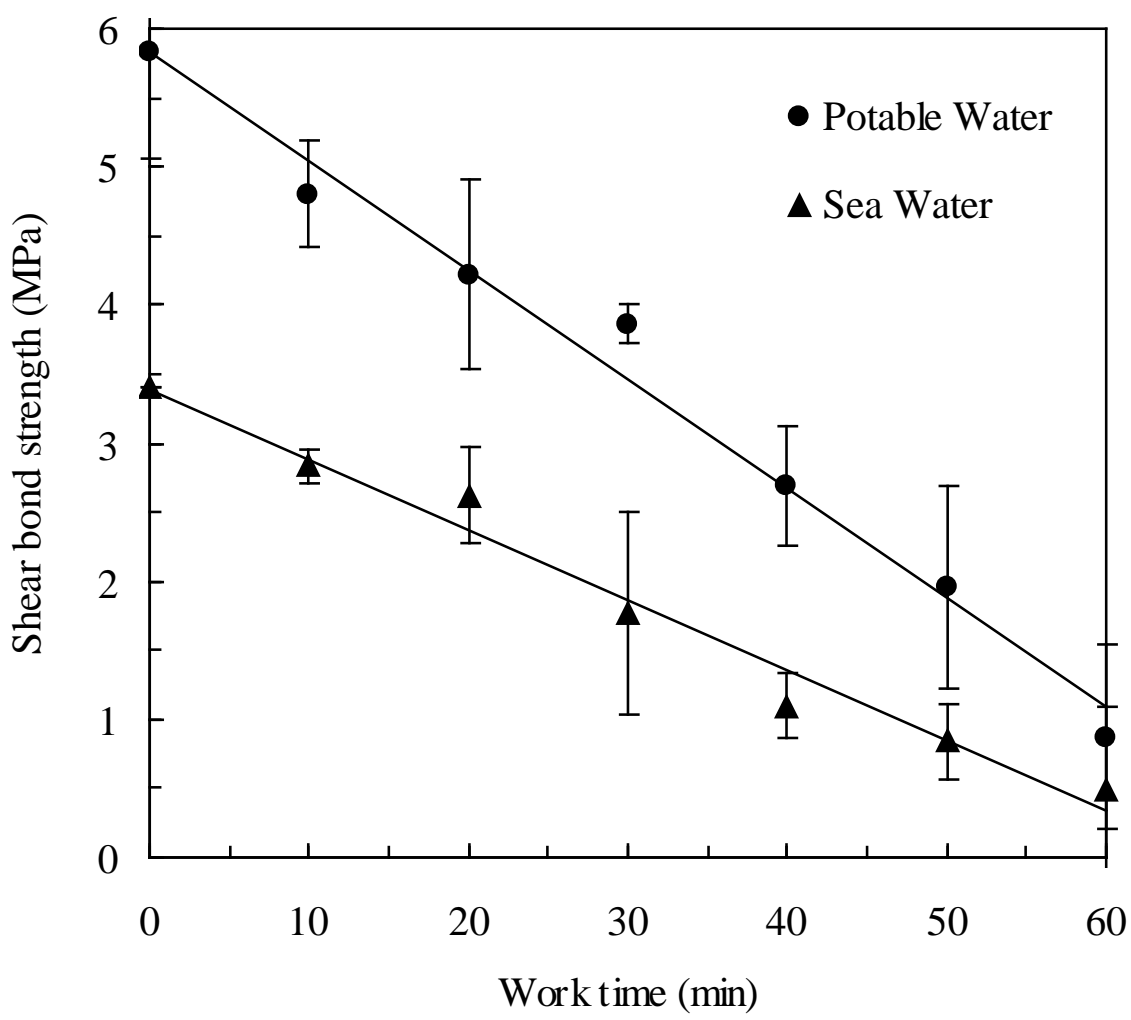

Figure 7: Effect of underwater work time on shear bond strength

\section{Conclusions}

Clear polycarbonate sheets can be bonded rapidly to underwater substrates using the commercial cyanoacrylate adhesive Loctite 454 spiked with the photoinitiator dibenzoylferrocene. In this regard the application process is critical. First a bead of the 
viscous adhesive is placed on the polycarbonate plate. On submersion a protective skin forms on the adhesive's surface owing to water-initiated polymerization. When the plate is pressed against the underwater substrate, the squeezing action causes unreacted adhesive to ooze out from the broken protective skin. It spreads radially outward to fill the gap between the two substrates. Simultaneously it displaces the water initially present. Full cure, throughout the adhesive layer, is guaranteed by photochemical polymerization. Initiation is triggered by illumination with a suitable blue light source, e.g. blue LED's (wavelength: $467 \mathrm{~nm}$ ). More specifically, a one minute exposure to this blue light with an intensity of ca. $5 \mathrm{~mW} / \mathrm{cm}^{2}$ was sufficient to reach the full ultimate bond strength of adhesive films with a thickness of 0.2 $\mathrm{mm}$ when the resin contained $0.2 \mathrm{wt} \%$ benzoylferrocene. Bond strength development was insensitive to the water temperature in the range of $1^{\circ} \mathrm{C}$ to $40^{\circ} \mathrm{C}$. Best adhesion performance, with the shear strength exceeding $5 \mathrm{MPa}$, was obtained when bonding one polycarbonate sheet to another. Strong bonds were also obtained when using other plastics but bonds to metal substrates were substantially weaker. Bond strengths were ca. 1 and $2 \mathrm{MPa}$ to anodised aluminium and stainless steel respectively. Finally, care should be taken to minimize the exposure to time water to avoid loss of bonding strength.

\section{Acknowledgements}

Financial and technical support from the Council for Scientific and Industrial Research for is acknowledged with gratitude.

\section{References}

[1] Mate, B., Mesecar, R. and Lagerquist, B. (2007) “The evolution of satellite-monitored radio tags for large whales: One laboratory’s experience”. Deep-Sea Res Pt II, 54(3-4): 224247.

[2] Lemarié, D.P., Smith, D.R., Villella, R.F. and Weller, D.A. (2000) "Evaluation of Tag Types and Adhesives for Marking Freshwater Mussels (Mollusca: Unionidae)”. J Shellfish Res, 19(1): 247-250.

[3] Ross, K.A., Thorpe, J.P., Norton, T.A. and Brand, A.R. (2001) “An assessment of some methods for tagging the Great Scallop, Pecten Maximus”. J. Mar. Biol. Assoc. U.K, 81(6): 975-977.

[4] http://www.garf.org/bestglue.html, 5 November 2006.

[5] Card, S.W. and West, J.R. (1988a) "Underwater Bonding of Surface Conforming Material”. US Patent 4,793,887, assigned to Morton Thiokol, Inc, Chicago, USA.

[6] Card, S.W. and West, J.R. (1988b) "System for Underwater and Cold Temperature Bonding”. US Patent 4,793,888, assigned to Morton Thiokol, Inc, Chicago, USA.

[7] Leonard, F. and Brandes, G. (1975) “Underwater Adhesive”. US Patent 3,896,077, assignee unknown, USA.

[8] Dolez, P. and Love, B. (2001) “Adhesive bonding as an alternative for underwater structural repair”. Paper presented at the Eleventh International Offshore and Polar Engineering Conference, Stavanger, Norway, 17-22 June 2001.

[9] Dolez, P., Marek, M. and Love, B.J. (2001) "Photopolymerizable acrylic resin: Effect of curing time and temperature”. J Appl Polym Sci, 82: 546-554.

[10] Dolez, P.I., Williams, C., Goff, A. and Love, B.J. (2003) "Properties of photopolymerisable acrylic adhesive for underwater bonding”. J Soc Underw Technol Lond, 25(4): 199-208.

[11] North Sea Resin, http://www.northsearesins.com/ [accessed 8 June 2007]

[12] Yamaguchi, Y., Palmer, B.J., Kutal, C., Wakamatsu, T. and Yang, D.B. (1998)

"Ferrocenes as anionic photoinitiators". Macromolecules, 31(15): 5155-5157.

[13] Palmer B.J. and Kutal, C. (1995) "A new photoinitiator for anionic polymerization”. Macromolecules, 28(4): 1328-1329. 
[14] Yamaguchi, Y. and Kutal, C. (1999) "Efficient photodissociation of anions from benzoyl-functionalized ferrocene complexes”. Inorg Chem, 38(21): 4861-4867.

[15] Yamaguchi, Y. and Kutal, C. (2000) "Benzoyl-substituted ferrocenes: An attractive new class of anionic photoinitiators”. Macromolecules, 33: 1152-1156.

[16] Kutal, C.R. and Yamaguchi, Y. (2000) "Substituted Benzoylferrocene Anionic

Photoinitiators” US Patent 6,127,445, assigned to The University of Georgia Research

Foundation Inc., Georgia, USA.

[17] Pappas, S.P. (1992) Radiation Curing - Science and Technology. Plenum Press: New York and London.

[18] Pepper, D.C. (1978) “Anionic and zwitterionic polymerisation of $\alpha$-cyanoacrylates”, J Polym Sci Polym Symp, 62: 65-77.

[19] Pepper, D.C. (1980) "Kinetics and mechanisms of zwitterionic polymerizations of alkyl cyanoacrylates”. Polym J, 12(9): 629-637.

[20] Mauguière-Guyonnet, F. Burget D. and Fouassier J.P. (2007) "On the inhibiting effect of phenolic compounds in the photopolymerization of acrylates under high-intensity and polychromatic UV/Visible lights”. J Applied Polym Sci, 103: 3285-3289.

[21] Chan, W.Y., Lough, A.J. and Manners, I (2007) "Photoreactivity and photopolymerization of silicon-bridged [1] ferrocenophanes in the presence of terpyridine initiators: Unprecedented cleavage of both iron-cyclopentadienyl bonds in the presence of chlorosilanes”. Chem Eur J, 13: 8867-8876.

[22] Tanabe, M., Vandermeulen, G.W.M., Chan, W.Y., Cyr, P.W., Vanderark, L., Rider, D.A. and Manners, I. (2006) "Photocontrolled living polymerizations”. Nature Materials, 5: 467470.

[23] Kinloch, A.J. (1981) Developments in Adhesives - 2. Applied Science Publishers: London and New York.

[24] Drain, K.F., Guthrie, J., Leung, C.L., Martin, F.R. and Otterburn, M.S. (1984) "The effect of moisture on the strength of steel-steel cyanoacrylate adhesive bonds". J Adhes, 17: 71-82.

[25] Drain, K.F., Guthrie, J., Leung, C.L., Martin, F.R. and Otterburn, M.S. (1985) "The effect of moisture on the strength of polycarbonate-cyanoacrylate adhesive bonds". Int $\mathrm{J}$ Adhes Adhes, 5(3): 133-136.

[26] Katti, D and Krishnamurti, N. (1999) "Anionic polymerization of alkyl cyanoacrylates: In vitro model studies for in vivo applications”. J Appl Polym Sci, 74: 336-344. 